Journal of Fundamental and Applied Sciences

ISSN 1112-9867

Available online at

http://www.jfas.info

\title{
ELECTROCHEMICAL STUDIES OF N'-FERROCENYLMETHYL-N'- PHENYLBENZOHYDRAZIDE AT GLASSY CARBON ELECTRODE IN DIFFERENT MEDIUM
}

\author{
A. Khelef*, N. S. Neghmouche and T. Lanez \\ VTRS laboratory, Institute of sciences and technology, University Centre of El-Oued, \\ B.P.789, 39000, El-Oued,Algeria
}

Received: 15 November 2011 / Accepted: 16 December 2011 / Published online: 31 December 2011

\begin{abstract}
The oxidative electrochemistry of N'-Ferrocenylmethyl-N'-Phenylbenzohydrazide $\mathrm{FcX}$ was studied in acetonitrile with tetrabutylammonium hexafluorophosphate as the supporting electrolyte and aqueous ethanol using the electrochemical technique. This study using cyclic (CV) and rotating disk electrode (RDE) voltammetry showed that the $\mathrm{FcX} / \mathrm{FcX} \mathrm{X}^{+}$redox couple is reversible in this electrolytes. The effects of changing the scan rate on the electrochemical behavior of ferrocene have been examined. A comparison of the electrochemical behavior of ferrocene and N'-Ferrocenylmethyl-N'Phenylbenzohydrazid have been examined.
\end{abstract}

Key words: Cyclic voltammetry, ferrocene, N'-Ferrocenylmethyl-N'-Phenylbenzohydrazid, half-wave potential.

\section{INTRODUCTION}

Ferrocene is a useful reference material for a lot of ferrocene derivatives it demonstrates good solubility, invariant redox potentials and excellent chemical and electrochemical reversibility in organic electrolytes [1].

Author Correspondence, e-mail: khelef2008@gmail.com

ICID: 1020759 
The reversibility of the $(\mathrm{Fc} / \mathrm{Fc}+)$ redox couple was established from polarographic studies [2] soon after the discovery of this organo-iron compound in 1951 by Kealy and Pauson [3]. Previous studies [4] of the electrochemistry of ferrocene and some of his derivatives in various solvents revealed a reversible one-electron process.

One of the ferrocene derivatives the compound N'-Ferrocenylmethyl-N'Phenylbenzohydrazide $\mathbf{3}$ are very important electron-transfer systems for molecular electronics owing to its characteristic redox behaviors[5], and they could also be expected to play a key role of an electron chemical probe of the electron-transfer process in biological molecules[6].

\section{RESULTS AND DISCUSSION}

\subsection{Synthesis}

(Ferrocenylmethyl)trimethylammonium iodide

The salt was synthesized according to literature procedures.[7]

\section{N'-Ferrocenylmethyl-N'-Phenylbenzohydrazide}

N'-Phenylbenzohydrazide was added to a well stirred solution of (Ferrocenylmethyl) trimethylammonium iodide in sodium-dried toluene. The resulting suspension was heated under reflux for $6 \mathrm{~h}$. It was then allowed to cool to room temperature and filtered. The filtrate was washed with water to remove any trace of unchanged quaternary ammonium salt. It was then dried and evaporated. The residue was recrystallized from ethanol to give N'-Ferrocenylmethyl-N'-Phenylbenzohydrazide as yellow-orange needles.

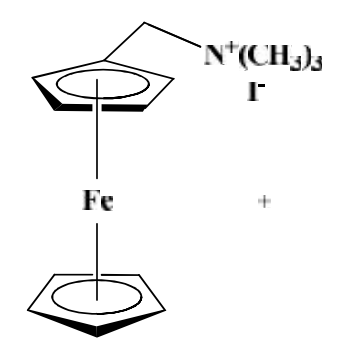

(1)

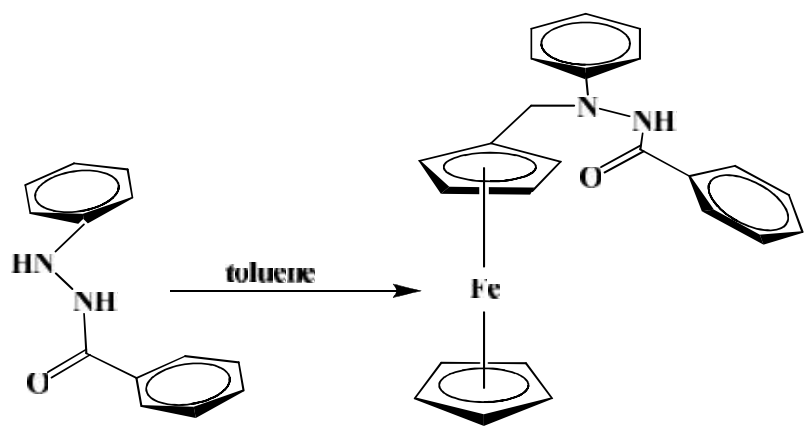

(2)

(3)

The proton N.M.R. spectrum of N'-Ferrocenylmethyl-N'-Phenylbenzohydrazide shows eleven peaks at $\delta \quad 4.12(\mathrm{t}, 2 \mathrm{H}, \mathrm{Hb}) ; \quad 4.15\left(\mathrm{~s}, 5 \mathrm{H}, \mathrm{C}_{5} \mathrm{H}_{5}\right) ; \quad 4.19(\mathrm{t}, 2 \mathrm{H}, \mathrm{Ha})$; 
4.60(s,2H, $\left.\mathrm{CH}_{2}\right) ; 6.86(\mathrm{t}, 1 \mathrm{H}) ; 6.95(\mathrm{~d}, 2 \mathrm{H}) ; 7.26(\mathrm{t}, 2 \mathrm{H}) ; 7.42(\mathrm{~m}, 2 \mathrm{H}) ; 7.53(\mathrm{t}, 1 \mathrm{H}) ; 7.62(\mathrm{~s}, 1 \mathrm{H})$ and 7.72ppm(m,2H, $\mathrm{C}_{6} \mathrm{H}_{5}$ and $\left.\mathrm{NH}\right)$. Figure 1.

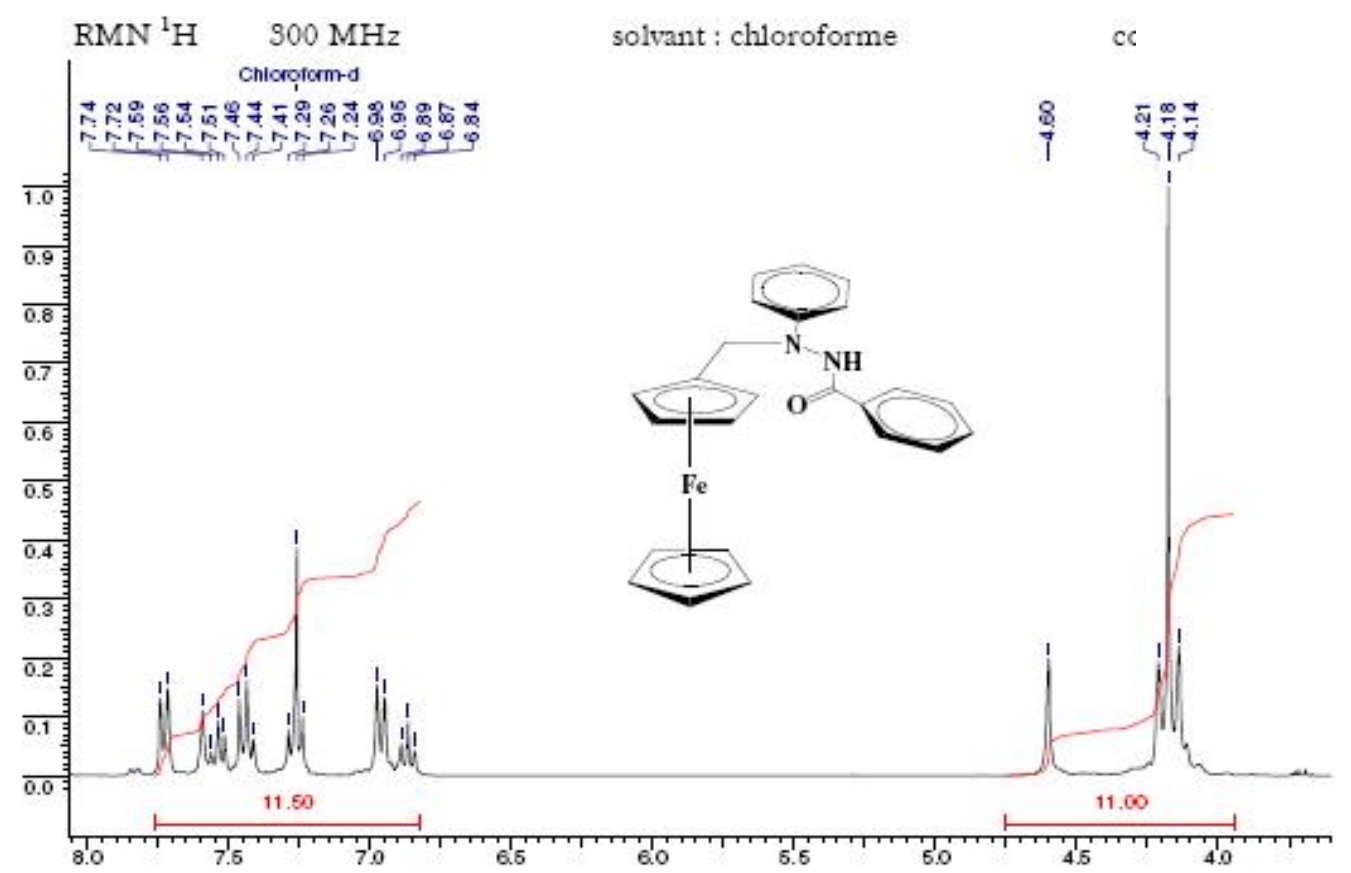

Fig.1. ${ }^{1}$ H. N.M.R spectrum of N'-Ferrocenylmethyl-N'-Phenylbenzohydrazide in $\mathrm{CDCl}_{3}$

The carbon N.M.R. spectrum also shows fourteen peaks, the first at $51.20 \mathrm{ppm}$ correspond to the carbon of the methylene group. The second at $68.60,69.80,77.60$ and $80.10 \mathrm{ppm}$ which correspond to the ten carbons of the ferrocene and the rest of the peaks at $113.40,119.75,127.20,128.30,129.20,132.00,132.80$ and 148.80 correspond to the carbon of the phenyl group and finely at 167.30 correspond to CO. Figure 2. 


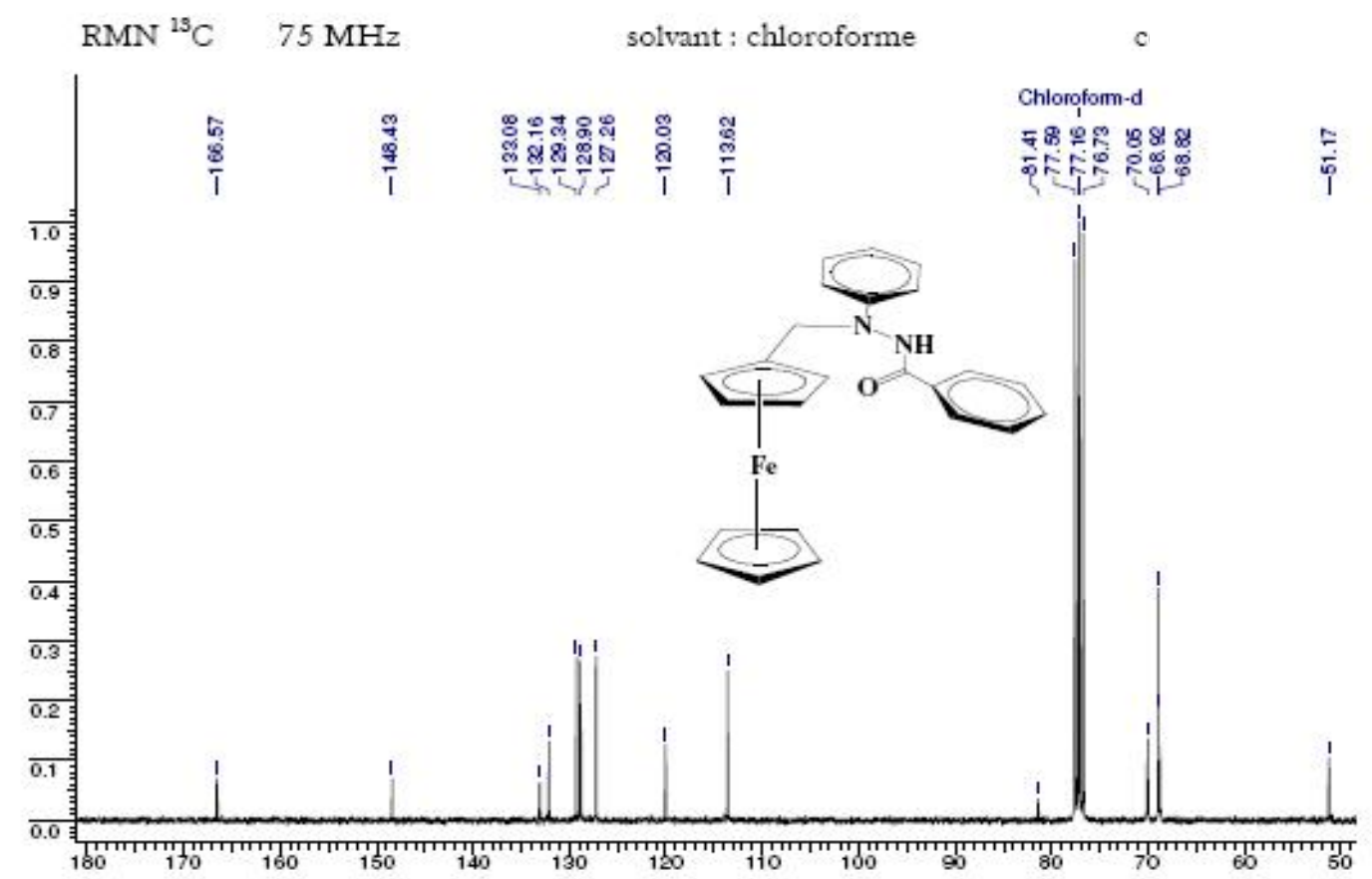

Fig.2. ${ }^{13}$ C. N.M.R spectrum of N'-Ferrocenylmethyl-N'-Phenylbenzohydrazide in $\mathrm{CDCl}_{3}$

The methylene group of the salt N'-Ferrocenylmethyl-N'-Phenylbenzohydrazide is characterised by its down orientation on the dept. spectrum . Figure 3.

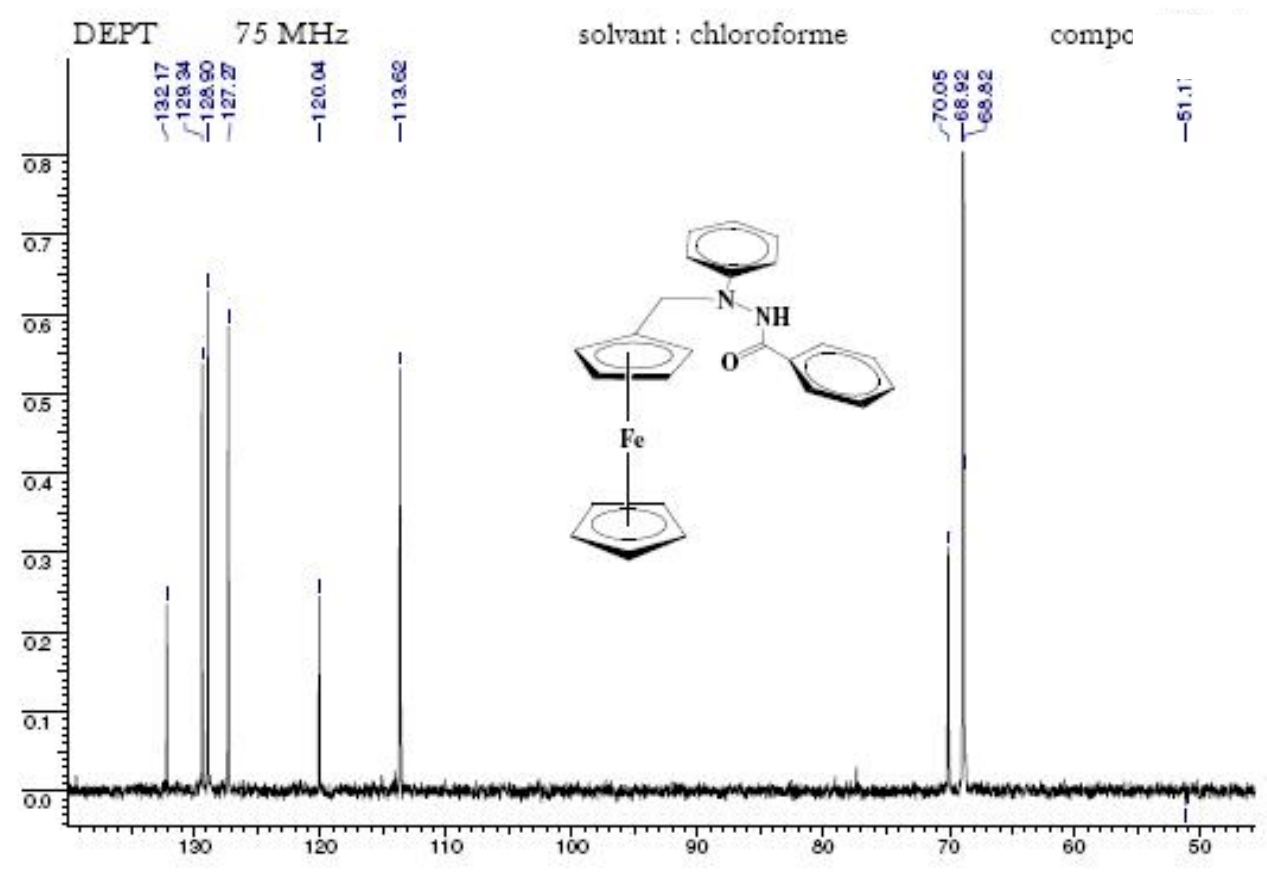

Fig.3. Dept spectrum of N'-Ferrocenylmethyl-N'-Phenylbenzohydrazide in $\mathrm{CDCl}_{3}$ 


\section{Electrochemical proprieties}

It is well known that N'-Ferrocenylmethyl-N'-Phenylbenzohydrazide FCX easily undergoes one electron oxidation to form ferrocenium cation $\mathrm{FCX}^{+}$in a reversible manner [5] figure (4). Thus, we investigated the electrochemical N'-FerrocenylmethylN'-Phenylbenzohydrazide behaviors in organic and aqueous mediums.

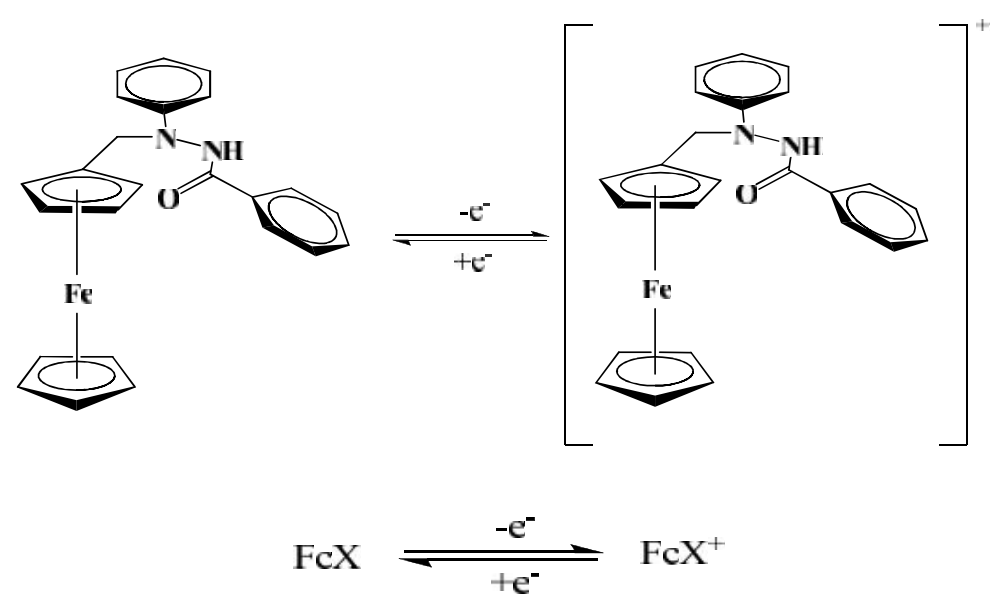

Fig.4. Reversible mono electronic oxidation of N'-Ferrocenylmethyl-N'Phenylbenzohydrazide

In previous work $[9,10]$ we reported the electrochemical behavior of $\mathrm{Fe}$ $(\mathrm{C} 5 \mathrm{H} 5) / \mathrm{Fe}(\mathrm{C} 5 \mathrm{H} 5) 2$ couple on a classy carbon and platinum electrode in organic medium $\left(\mathrm{CH}_{2} \mathrm{Cl}_{2}\right)$ and aqueous medium (ethanol/aq. $\left.\mathrm{H}_{2} \mathrm{SO}_{4}\right)$. In present work, we report electrochemical behavior of N'-Ferrocenylmethyl-N'-Phenylbenzohydrazide in acetonitrile and in aqueous ethanol. Electrochemical behavior of $\mathrm{FcX}$ and $\mathrm{FcX}^{+}$couple in both solutions was investigated by cyclic voltammetry using a classy carbon electrode.

\section{EXPERIMENTAL}

\subsection{Chemicals}

All chemicals were of reagent grade and were used without further purification. Solvents were purified according to standard methods [8]. All reactions were conducted under nitrogen. Solutions were dried over anhydrous magnesium sulphate and evaporated under reduced pressure using a rotary evaporator. 
The electrolyte salt tetrabutylammonium tetrafluoroborate $\mathrm{Bu}_{4} \mathrm{NBF}_{4}$ (Fluka, electrochemical grade $99 \%$ purity) was dried for $1 \mathrm{~h}$ at $105{ }^{\circ} \mathrm{C}$ before use. Acitonitrile (Sigma-Aldrich, 99.9\% purity) was dried over molecular sieves before use. Argon plunging tube bottle was provided by ENGI (Enterprise nationale des gaz industriels). All the freshly prepared solutions were degassed under argon gas flow before experiments.

\subsection{Electrochemical studies}

Electrochemical characterization was carried out on a potentiostat type voltalab 40 of radiometer, with a three-stand electrode cell. Cyclic voltammetric experiments were performed in deoxygenated $\mathrm{CH}_{3} \mathrm{CN}$ and aqueous ethanol solutions of N'Ferrocenylmethyl-N'-Phenylbenzohydrazide 3 with respectively $10^{-1} \mathrm{M}$ of $\mathrm{Bu}_{4} \mathrm{NBF}_{4}$ and $\mathrm{H}_{2} \mathrm{SO}_{4}$ as supporting electrolyte and N'-Ferrocenylmethyl-N'-Phenylbenzohydrazide 3 concentration of $10^{-3} \mathrm{M}$. The three electrodes used were glassy carbon disk as the working electrode, saturated calomel electrode as a reference electrode, and Pt wire as an auxiliary electrode. The working electrode was polished with $0.05 \mu \mathrm{m}$ alumina slurry for 1-2 minutes, and then rinsed with double-distilled and deionized water. This cleaning process is done before each cyclic voltammetry experiment .

Cyclic voltammetry was measured for an acetonitrile of ferrocene and N'Ferrocenylmethyl-N'-Phenylbenzohydrazide at scan rates equal to 50, 100, 300, and $500 \mathrm{mv} \mathrm{s}^{-1}$ (fig5) .
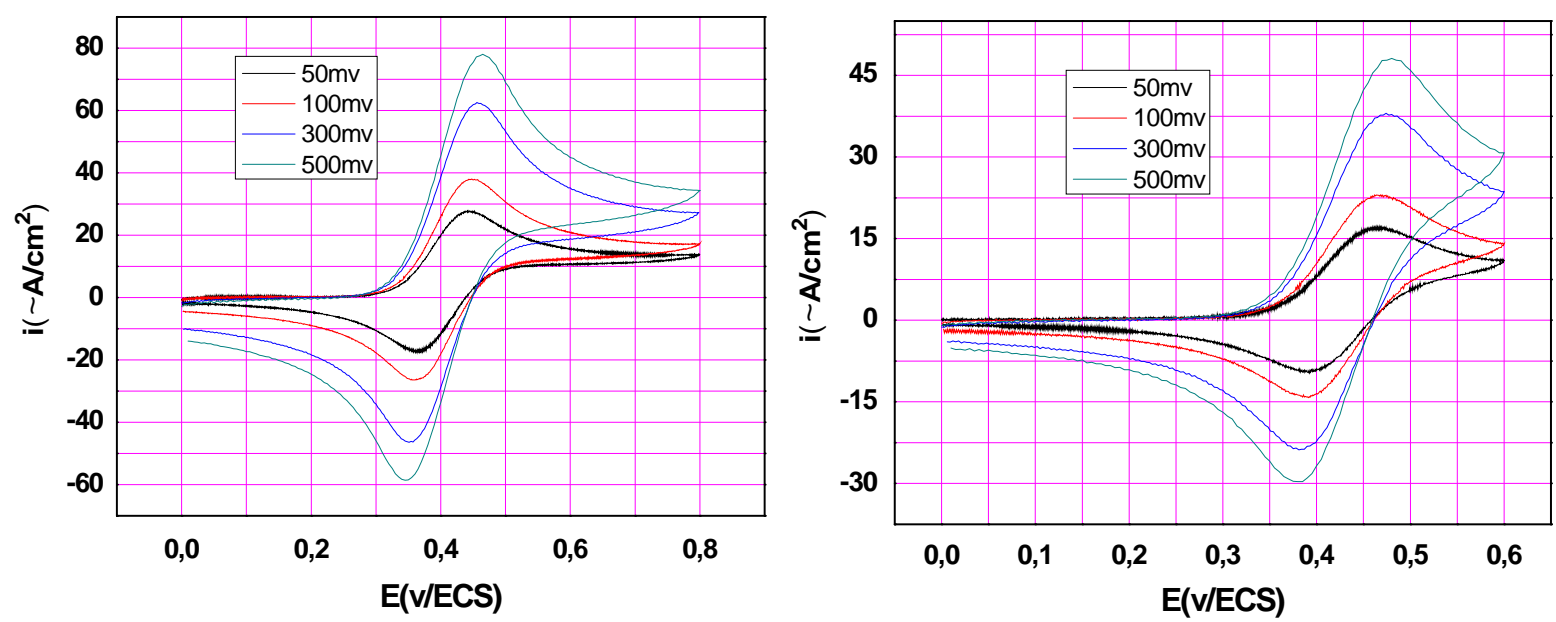

Fig.5. cyclic voltammetry of ferrocene and compound $31 \mathrm{mM}$ and $100 \mathrm{mM} \mathrm{Bu}_{4} \mathrm{NBF}_{4}$ in $\mathrm{CH}_{3} \mathrm{CN}$ at $2 \mathrm{~mm}$ diameter glassy carbon working electrode, Pt counter electrode, and CSE reference electrode at $\left(0.05,0.10,0.30,0.50 \mathrm{~V} . \mathrm{s}^{-1}\right)$. 
Relevant electrochemical data obtained from these experiments are summarized in table1

Table 1. Electrochemical data for the oxidation of ferrocene and compound $\mathbf{3}$ measured at $25^{\circ} \mathrm{C}$ in $10^{-1} \mathrm{M} \mathrm{Bu} 4 \mathrm{NBF}_{4} / \mathrm{CH}_{3} \mathrm{CN}$.

\begin{tabular}{|l|c|c|c|c|c|c|c|c|}
\hline Compound & $\mathrm{v}$ & $\mathrm{I}_{\mathrm{pa}}$ & $\mathrm{I}_{\mathrm{pc}}$ & $\mathrm{Ep}_{\mathrm{a}}$ & $\mathrm{Ep}_{\mathrm{c}}$ & $\mathrm{Ep}_{\mathrm{a} 1-} \mathrm{Ep}_{\mathrm{c} 1}$ & $\mathrm{E}_{1 / 2}$ & $\mathrm{I}_{\mathrm{pc}} / \mathrm{I}_{\mathrm{pa}}$ \\
\hline \multirow{5}{*}{ Ferrocene } & 500 & 78 & -82 & 465 & 345 & 120 & 392 & 0,95 \\
& 300 & 62,5 & $-64,4$ & 456 & 351 & 105 & 388 & 0,97 \\
& 100 & 38 & $-38,8$ & 448 & 359 & 89 & 383 & 0,98 \\
& 50 & 27,75 & $-28,29$ & 440,5 & 360,5 & 80 & 381 & 0,98 \\
\hline \multirow{5}{*}{ Compound 3 3} & 500 & 48,12 & -51 & 480 & 385 & 95 & 412 & 0,94 \\
& 300 & 38 & $-39,8$ & 474 & 381 & 93 & 409 & 0,95 \\
& 100 & 23 & -24 & 468 & 391 & 77 & 408 & 0,96 \\
& 50 & 17,2 & $-17,47$ & 465 & 392 & 73 & 402 & 0,98 \\
\hline
\end{tabular}

These studies showed that when ferrocene is scanned at scan rate equal to $50 \mathrm{mv} . \mathrm{s}^{-1}$ it gives one oxidation peak Epa at $440.5 \mathrm{mv}$, and also one reduction peak Epc at 360.5, these two peaks are attributed to the redox couple $\mathrm{Cp}_{2} \mathrm{Fe}(\mathrm{III}) / \mathrm{Cp}_{2}$ (II). Figure 5a. The same results are obtained even one ferrocene is subjected to a successive scan equal to 10 cycles. The unchanged in shape of the voltammogram of ferrocene under this successive scan means that the compound is electrochemical very stable. The voltammograms obtained at different scan rate from 50 to $500 \mathrm{mv} \cdot \mathrm{s}^{-1}$ indicate in the first hand that ferrocene kept its reversible character and the intensity of courant increase with the increase of the scan rate.

The voltammograms of N'-Ferrocenylmethyl-N'-Phenylbenzohydrazide 3, obtained at $50 \mathrm{mv} \cdot \mathrm{s}^{-1}$, showed one oxidation peak at $465 \mathrm{mv}$ and one reduction peak at $392 \mathrm{mv}$ which are attributed to the $\mathrm{FcX} / \mathrm{FcX}^{+}$couple. Also the oxidation of this compound appeared to be Nerstian and diffusion controlled. Plots of $\left(i_{p}\right)_{\text {anod }}$ verses the square root of the scan rate $\left(\mathrm{v}^{1 / 2}\right)$ were linear. The peak-to peak separations are, however, significantly greater than the ideal value of $60 \mathrm{mvs}^{-1}$ for a fully reversible one-electron processes. This may be due to a combination of uncompensated solution resistance and slightly slow electron-transfer kinetics. The $E_{1 / 2}$ of the studied compound is $402 \mathrm{mv}$ is higher compared to the ferrocene $381 \mathrm{mv}$. This difference may be explained by the influence of the electron withdrawing $\mathrm{N}$-Phenylbenzohydrazide group in the 
N'-Ferrocenylmethyl-N'-Phenylbenzohydrazide. Other relevant electrochemical data obtained from these experiments are summarized in table 1.

Cyclic voltammetry was measured for an aqueous ethanol solutions of ferrocene and $\mathrm{N}^{\prime}-$ Ferrocenylmethyl-N'-Phenylbenzohydrazide at scan rates equal to 50,100,300, and $500 \mathrm{mv} \mathrm{s}^{-1}$ (fig6) .
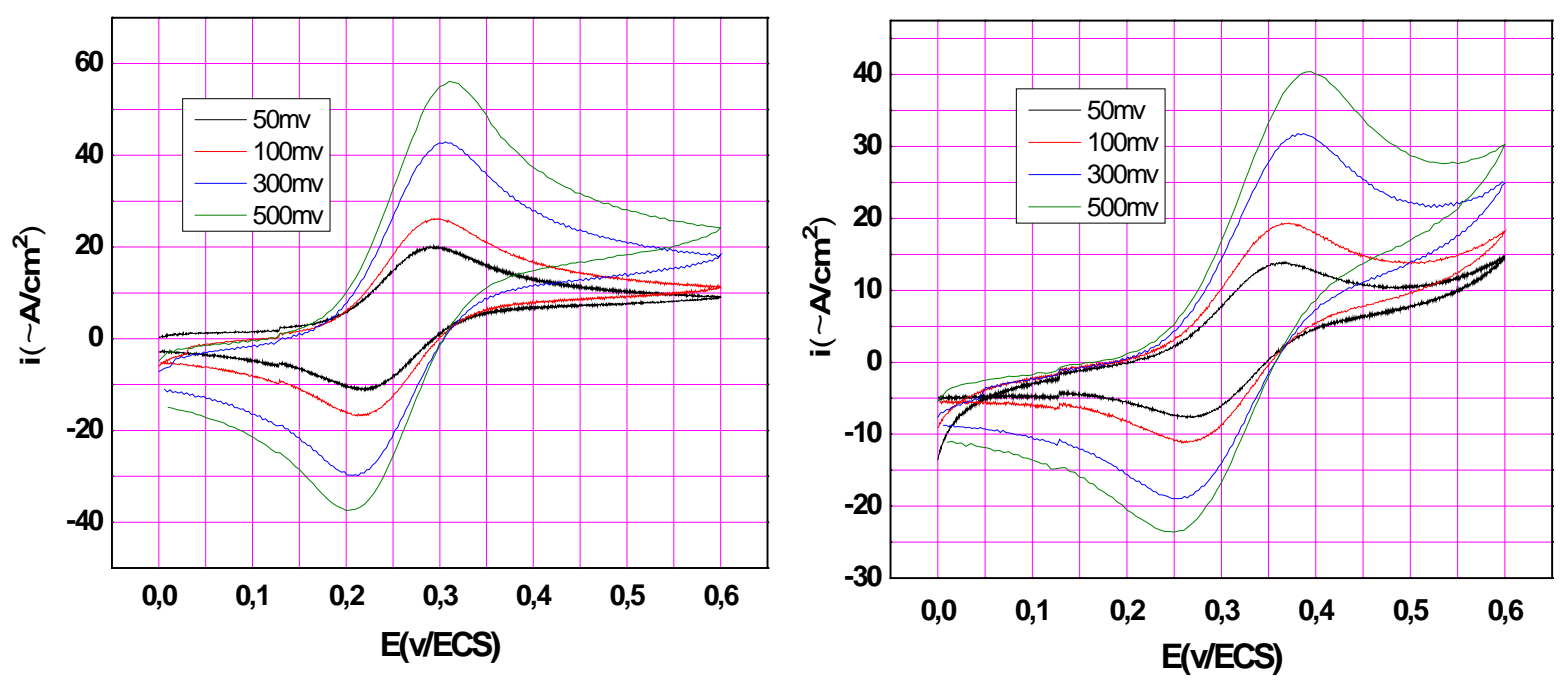

Fig.6. cyclic voltammetry of ferrocene and compound $32 \mathrm{mM}$ in ethanol/aq. $\mathrm{H}_{2} \mathrm{SO}_{4}$ at 2 mm diameter glassy carbon working electrode, Pt counter electrode, and CSE reference electrode at $\left(0.05,0.10,0.30,0.50 \mathrm{~V} . \mathrm{s}^{-1}\right)$.

Relevant electrochemical data obtained from these experiments are summarized in table2

Table 2. Electrochemical data for the oxidation of ferrocene and compound $\mathbf{3}$ measured at $25{ }^{\circ} \mathrm{C}$ in aqueous medium (ethanol/aq. $\mathrm{H}_{2} \mathrm{SO}_{4}$ ).

\begin{tabular}{|l|c|l|l|c|c|c|c|c|}
\hline Compound & $\mathrm{v}$ & $\mathrm{I}_{\mathrm{pa}}$ & $\mathrm{I}_{\mathrm{pc}}$ & $\mathrm{Ep}_{\mathrm{a}}$ & $\mathrm{Ep}_{\mathrm{c}}$ & $\mathrm{Ep}_{\mathrm{al}}-\mathrm{Ep}_{\mathrm{cl}}$ & $\mathrm{E}_{1 / 2}$ & $\mathrm{I}_{\mathrm{pc}} \mathrm{I}_{\mathrm{pa}}$ \\
\hline \multirow{5}{*}{ Ferrocene } & 500 & 56,12 & $-55,4$ & 310 & 205 & 105 & 242 & 1,01 \\
& 300 & 42,9 & $-42,07$ & 306 & 213 & 93 & 238 & 1,02 \\
& 100 & 26,2 & $-25,07$ & 295 & 212 & 83 & 233 & 1,05 \\
& 50 & 20,18 & $-18,35$ & 293,5 & 219,5 & 74 & 226,5 & 1,10 \\
\hline \multirow{5}{*}{ Compound 3 } & 500 & 40,4 & $-40,6$ & 395 & 250 & 145 & 310 & 1,00 \\
& 300 & 31,8 & $-31,8$ & 381 & 252 & 129 & 306 & 1,00 \\
& 100 & 19,4 & $-19,8$ & 372 & 258 & 114 & 297 & 0,98 \\
& 50 & 13,93 & $-14,4$ & 367,5 & 270 & 97,5 & 295,5 & 0,97 \\
\hline
\end{tabular}


The oxidation of this compound $\mathbf{3}$ appeared to be Nerstian and diffusion controlled. Plots of $\left(i_{p}\right)_{\text {anod }}$ verses the square root of the scan rate $\left(v^{1 / 2}\right)$ were linear. The peak-to peak separations are, however, significantly greater than the ideal value of $60 \mathrm{mvs}^{-1}$ for a fully reversible one-electron processes. This may be due to a combination of uncompensated solution resistance and slightly slow electron-transfer kinetics. The $\mathrm{E}_{1 / 2}$ of the studied compound obtained at $50 \mathrm{mv}^{-1}$ is $295.5 \mathrm{mv}$ is higher compared to the ferrocene $265.5 \mathrm{mv}$. This difference may be explained by the influence of the electron withdrawing N'-Phenylbenzohydrazide group in the N'-Ferrocenylmethyl-N'Phenylbenzohydrazide. Other relevant electrochemical data obtained from these experiments are summarized in table 2.

\section{CONCLUSION}

Voltammetry analysis on a fixed electrode of N'-Ferrocenylmethyl-N'Phenylbenzohydrazide in aqueous and organic solutions indicates that the electrochemical reaction of N'-Ferrocenylmethyl-N'-Phenylbenzohydrazide in both studied solutions is a diffusion controlled process, namely, electrochemical process and show that the electron withdrawing N'-Phenylbenzohydrazide group introduced to the ferrocene influences the redox potential of the iron centre. This is may be due to the non-insulating effect of methylene between the N'-Phenylbenzohydrazide group and the cyclopentadienyl ring of ferrocene. In addition Ep for the ferrocene in $\mathrm{CH}_{3} \mathrm{CN}$ is grater than Ep in aq. ethanol, this difference can be attributed to the difference in diffusion coefficient between ferrocene in each medium which is a major contributor. However there is a minor contributor which is related to the difference in the solution resistance of the two electrochemical medium.

\section{REFERENCES}

[1] Gritzner G. Pure Appl. Chem. 1984, 56, 461.

[2] Page J. A., Wilkinson G. J. Am. Chem. Soc. 1952, 74, 6149.

[3] Kealy T. J., Pauson P. L. Nature. 1951, 168, 1039.

[4] Tsierkezos N. J. Solution Chem. 2007, 36, 289.

[5] Terki B., Chérifi N., Lanez T*. and Belaidi S. Asian J. Chem. 2006, 18(3).

[6] Bath B. D., Scott E. R., Phipps J. B., White H. S. J. Pharm. Sci. 2000, 89(12), $1537-$ 1549. 
[7] Osgerby J. M. and Pauson P. L. J. Chem. Soc. 1958, 642.

[8] Perrin D. D. and Armarego W. L. F. 1988, Purification of laboratory Chemicals, Pergamon Press, New York.

[9] Neghmouche N. S., Khelef A., Lanez T. Rev. sci. fond. app. 2009, 1(1), 23-30.

[10] Neghmouche N. S., Khelef A., Lanez T. Research Journal of Pharmaceutical, Biological and Chemical Sciences RJPBCS. 2010, 1(1), 76-82.

How to cite this article

Khelef A, Neghmouche N S and Lanez T. Electrochemical studies of n'ferrocenylmethyl-n'-phenylbenzohydrazide at glassy carbon electrode in different medium. J Fundam Appl Sci. 2011, 3(2), 200-209. 